\title{
Designing Experiments using Digital Fabrication in Structural Dynamics
}

Rolando Chacón ${ }^{a}$, Sergio Oller ${ }^{b}$

a Department of Civil and Environmental Engineering School of Civil Engineering. Universitat Politècnica de Catalunya. Barcelona. Spain

b Department of Civil and Environmental Engineering School of Civil Engineering. Universitat Politècnica de Catalunya. Barcelona. Spain

In engineering, traditional approaches aimed at teaching concepts of dynamics to engineering students include the study of a dense yet sequential theoretical development of proofs and exercises. Seldom, structural dynamics are taught experimentally in laboratories since these facilities should be provided with expensive equipment such as wave generators, data-acquisition systems and heavily wired deployments with sensors. In this paper, the design of an experimental experience in the classroom based upon digital fabrication and modeling tools related to structural dynamics is presented. In particular, all experimental deployments are conceived with low-cost, open source equipment. Hardware includes Arduino-based open-source electronics whereas Software is based upon object-oriented open-source codes for the development of physical simulations. The set of experiments as well as the physical simulations are reproducible and scalable in classroom-based environments.

\section{Introduction}

For engineers of various areas, the study of vibrations and dynamics is an important cornerstone. In the particular case of civil and structural engineering, the vibration of beams and frames represent one of the first topics to be discussed in traditional courses of structural dynamics. Generally, these students have taken introductory and/or advanced courses of statics at this point 


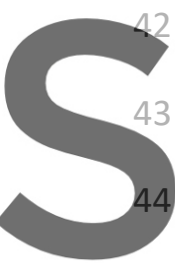

45

of their curricula. Both dynamics and statics erect the frame of the vast field labeled in civil engineering as structural analysis. In dynamics, basic concepts such as damping, frequency, resonance or isolation are of an utmost importance when understanding more complex phenomena related to single- or multi-degree of freedom systems. Classic textbooks such as (Chopra 2007; Clough and Penzien 2003; Paz and Leigh 2003) provide detailed information about the basics, the development of the formulae as well as the application of such concepts in seismic and structural engineering.

Moreover, open electronics have become considerably popular among entrepreneurs, designers, computer scientists, hobbyists and more recently, engineering educators. A vast array of low-cost, open source microcontroller platforms such as (Arduino 2016, Raspberry Pi 2016 and Adafruit 2016) are nowadays commercially available and economically more affordable than professional

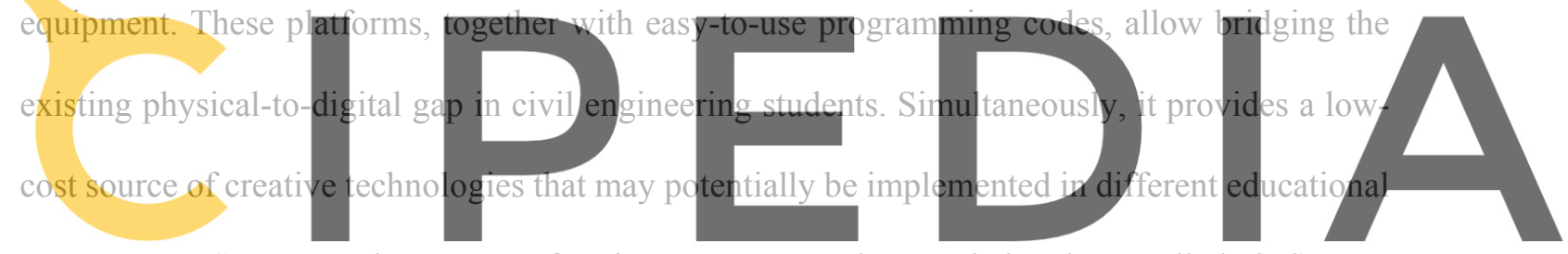
ecosystems. Sensors and actuators of various sources can be coupled and controlled via i) open free at https//www.scipedia.com to download the version without the watermark applications. Active online communities are nowadays feeding the web with endiess possibilities related to coding, electronics and physical applications of such technologies. Together with additive $3 \mathrm{D}$ printing and subtractive laser-cutting, digital fabrication and modeling (DFM) is continuously entering into schools and universities as an important part of the curricula.

The aim of this paper is to present the design of a hands-on set of experiments related to structural dynamics. Teaching includes an initial understanding of DFM tools and the reproduction of a set of experiments related to structural dynamics developed with open-source Hardware and Software. The aim of the experimental experience is to provide to students tools related not only to structural dynamics but also, to creative DFM technologies. Particular goals of the proposal include: 
- Providing a theoretical framework related to structural dynamics, including concepts of frequency, period, damping, resonance and the equations of motion.

- Providing concepts of the open prototyping platform Arduino and its circuitry.

- Providing an introduction to object-oriented physical simulations of dynamic systems using Processing 2.0 (Processing 2016), an open-source language and development environment built on top of the Java programming language.

- Providing initial computational tools for using Arduino and Processing as an opensource, low-cost data acquisition system that may be used in the classroom with scale-

69
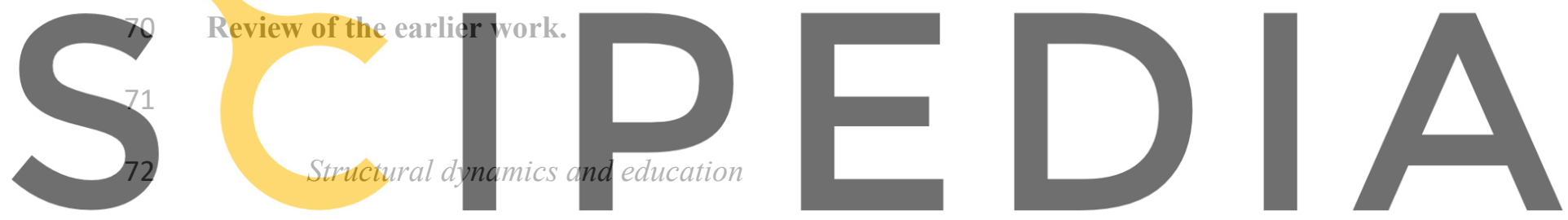

73

The importance of structural dynamics gives the topic a major position in civil,

mechanical and geological engineering. Classic textbooks with a vast array of exercises are available (Chopra 2007; Clough and Penzien 2003; Paz and Leigh 2003). Experimental dynamics in the particular case of beams also play a continuous primary role in textbooks (Blanco et al. 2007) and state-of-the-art research (Chen et al. 2014; Ozcelik et al. 2013; Adhikari et al. 2009). From an educational perspective, pedagogic platforms related to structural dynamics are not infrequent. Most of them are, however, based upon numerical simulations in desktop computers. Katsanos et al. (2014) developed educational computational tools for the seismic analysis of reinforced concrete. The platform was developed with Matlab (Matlab 2016) and accounts not only for the building structural dynamics but also, for the soil-structure interaction. With the aim of providing an educational learning environment for applications in dynamics, Elgamal et 

number of exercises. The platform has been used in several universities in California and includes Hardware developed by the authors as well as visual tools developed with intuitive game-like platform for the understanding of structural analysis via 3D, FEbased models.

92
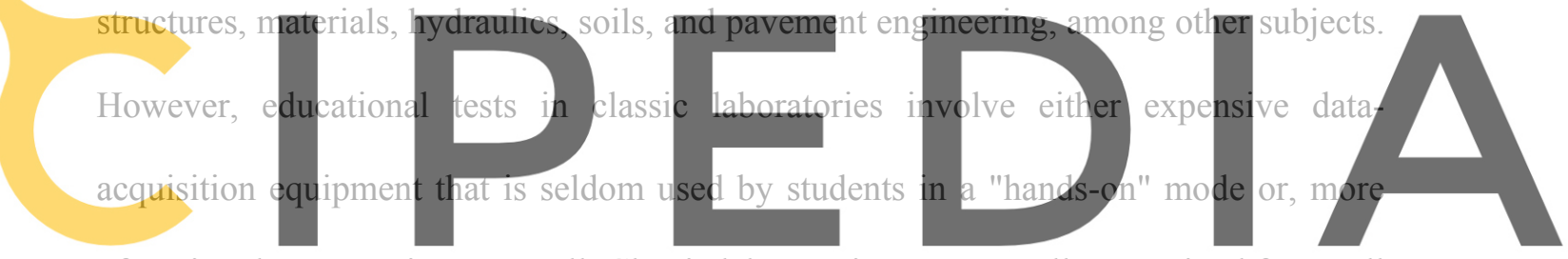

often, involve no equipment at all. Classic laboratories are generally conceived for small

Register for free at https//www.scipedia.com to download the version without the watermark

103

104

105

106

107

108

109

110

laboratory staff that provides raw data to students for further analysis. This is particularly common in large universities with a considerable amount of students or in countries in which laboratories are not equipped with sufficient material for both research and education. In particular, in civil engineering, at the end of their degrees, even if students are satisfactorily acquainted with the physical phenomena, a basic understanding of the electronics involved in measurement and data-acquisition is less frequent among them. These facts do not contribute to bridging the existing physical-to-digital gap among engineering students that is absolutely necessary to overcome in the digital society. With the advent of open platforms, students of other branches of engineering such as robotics (Valera et al. 2014), control engineering (Ionescu et al. 2013), real-time systems (CruzMartín et al. 2012) or chemistry (Guo et al. 2007) are increasingly acquainted with data- 

and Software. The convergence of 3D printing, open Hardware and open Software may revolutionize the educational experimental training nowadays provided in high schools as well as in technical universities (Pearce 2014). A deeper understanding of such possibilities may also help fostering entrepreneurial, innovative skills in civil engineering

Examples of usage of open-source boards in engineering applications are not infrequent,
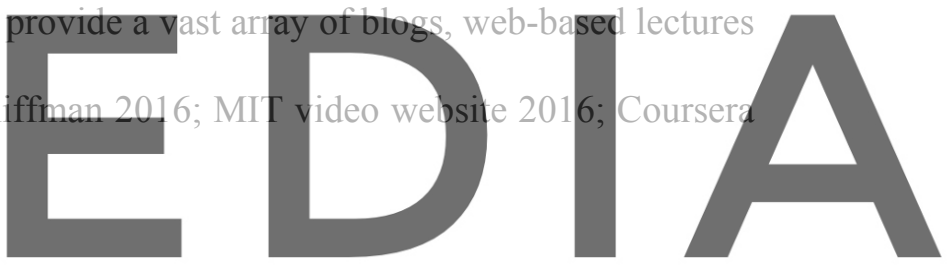

129

\section{Register for}

131 the integration of BIM. 
Processing and Arduino were chosen as the Software and Hardware combinations for the development of the educational experience due to availability at the school and the open-source nature of both. In addition, the Integrated Development Environment (IDE) of both platforms is very similar. Figure 1 shows both IDEs as well as a scheme of the coding syntaxes. Both cases include a setup() function (run once) and a $\operatorname{draw}()$ or loop () function, which runs repeatedly. For the case of Processing (Fig. 1(a)), the draw function allows developing computer simulations involving movement of objects. In the case of Arduino (Fig. 2(b)), the loop function defines all

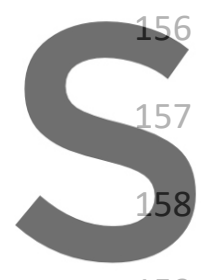

159

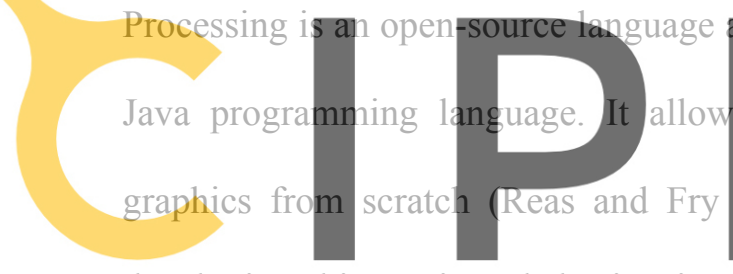

developing object-oriented physics simu

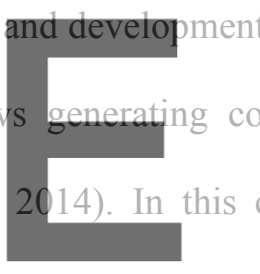

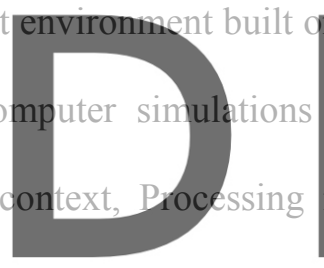

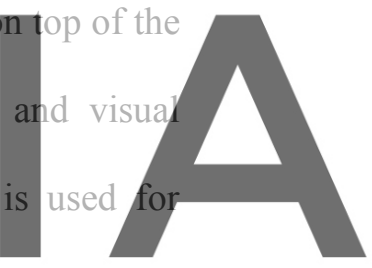

161

One of the most efficient ways of developing simulations of motion of bodies according to physical laws is the use of an object-oriented approach. Classes that depict the behavior of objects such as balls, springs or rigid bodies may be defined separately. In the main code, new objects can be called and used by applying methods defined in the classes. Processing includes widely depicted in-built classes defining the behavior of vectors or images (PVector, PImage). The result is a simpler setup()-draw() code.

The Arduino board 

to computers is performed via USB (for uploading programs or providing power) and an alternative power supply connection (batteries or similar) may also be used in boards in which programs are already uploaded. The board is open and any program following the Arduino syntax can be uploaded and erased as needed. The board can be programmed to sense the environment by receiving analog inputs from many sensors, and/or to affect its surroundings by controlling lights, motors, and other actuators or digital devices.

179

180

The typical structure of Arduino programs is fairly simple can be divided in three main

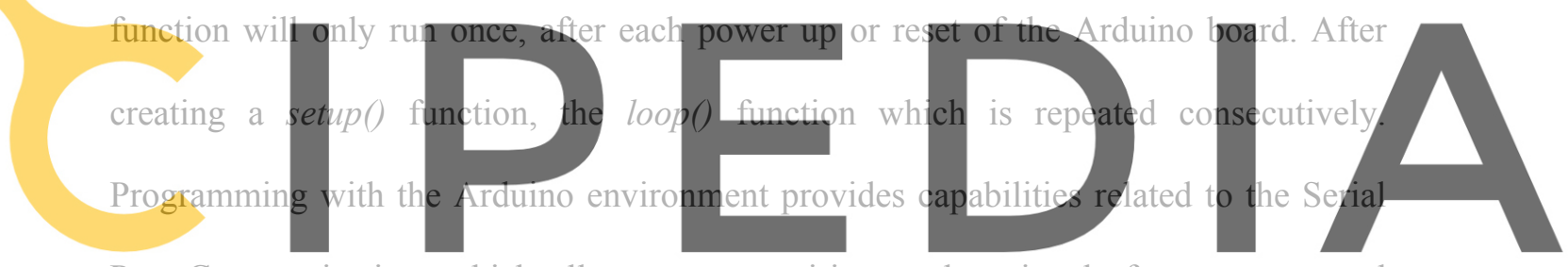

For educational purposes, experimental tests with enriched content related to digital fabrication are conceived. This experience represents a part of a vaster course on structural dynamics including theoretical background and exercises presented in a classic fashion. The entire course 


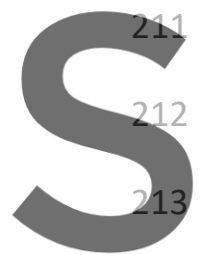

214

\section{Register for}

216

217 Table 1 displays the organization and schedule of the classroom as well as the educational

- Processing (6 hours). Introduction to OOVP with vectors and trigonometry and subsequently, simulation of two well-known dynamic systems, the pendulum and the spring.

\section{- Arduino (6 hours). Introduction to Arduino circuitry by learning the basics, which include}

the control of a LED blink, introduction to sensing with Light Dependent Resistor LDR.

Usage of the serial port to visualize analog magnitudes and the control of small motors and servos. Subsequently, design of two tests in simple cantilever beams.

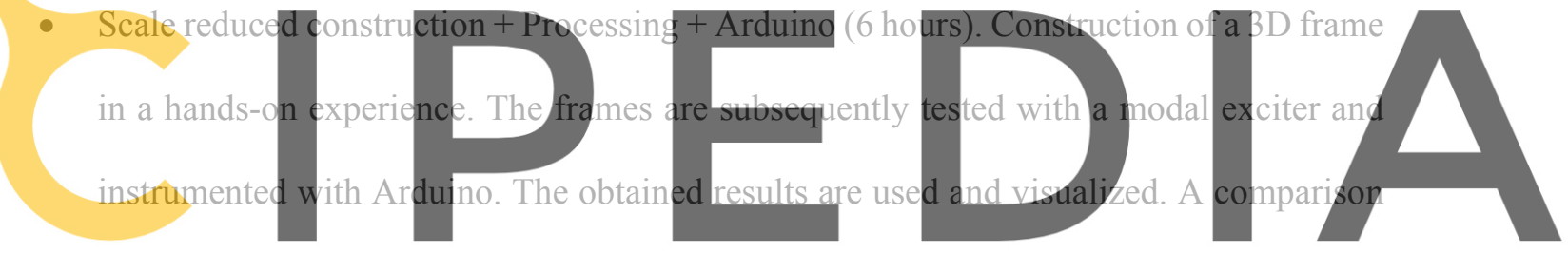

with theoretical analysis of n-degrees of freedom planar systems is performed for the sake

- Master classes (Intro and Core) are given by the facilitator with a hands-on perspective for the first and second part. The students use desktop computers and electronic equipment in groups or individually. The third part is entirely driven by students as the constructors of 3D models.

- Homework (compulsory submission) are aimed at developing physical simulations or at analyzing physical results obtained in real models. 
In the following, details concerning each part of the designed class classroom are provided. submission of creative projects. These creative projects may be also rewarded by featuring the results in social networks or in school days.

Finally, it is important to bear in mind that these 18 hours are part of a vaster course (60 hours in total) in which traditional lectures and evaluations are performed.

First, a 2-hour long introduction related to motion, vectors, location, velocity and
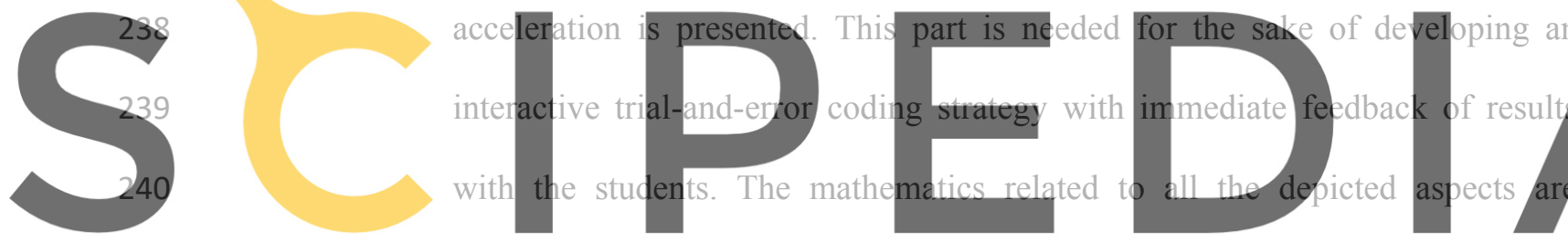

241

customized by students from scratch. The location of an object (rectangle, circle,

Register for free at https//www.scipedia.com to download the version without the wat

242

243

244

245

246

247

248

249

250

251

252
After all initial information related to vectors and to trigonometry is depicted with the corresponding motion equations, the main core of this part is the development of two different dynamic systems: A pendulum and a spring.

For the former, the students need to use basic concepts related to vectors and trigonometry for the development of a simple yet realistic physical simulation of a moving object whose position is repeatedly updated. At each frame, forces are 
applied to the object (self-weight, damping and anchor) and thus, acceleration, velocity and location of the object are updated. Figure 3 displays the result obtained by students in the Processing canvas as well as a scheme of the applied forces.

258

For the latter, the students need to use concepts related to Hooke's law for the development of a simple yet realistic physical simulation of a moving spring whose position is repeatedly updated. At each frame, the self-weight and the
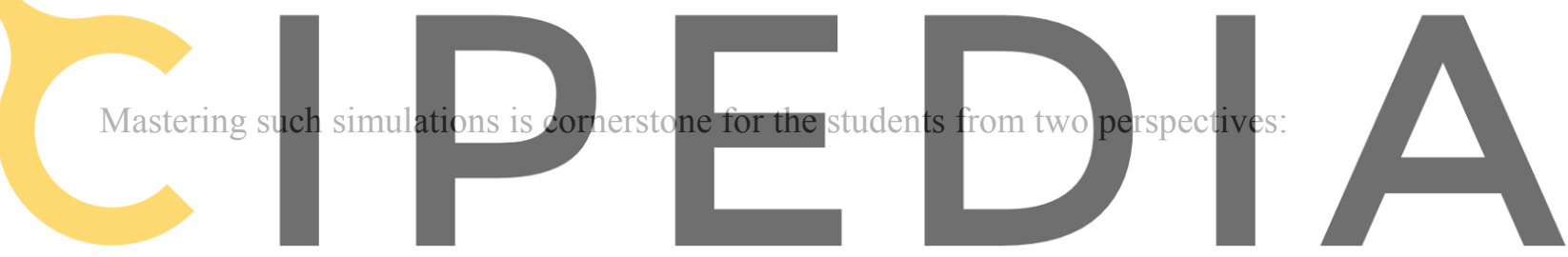

269

- The students are required to submit a compulsory homework in which a more Register for free at https//www.scipedia.com to download the version without the watermark 270 sophisticated simulation is assigned. Beams, Frames or multi-springs systems are visually simulated (all systems with a single degree of freedom).

272

- The students get acquainted with the object-oriented syntaxes of Processing, which is similar and subsequently, easier to follow in Arduino IDE.

275

276

277

Physical experiments. Free vibrations and harmonic oscillations

279

First, a 2-hour long introduction related to basic electronics is presented. The students are provided with kits containing the following equipment: 
- Arduino UNO board with USB cable

- $\quad$ Light dependent resistors (LDR)

- A potentiometer

- Buttons

- A breadboard

- A 3-axis accelerometer

291

- A small 9V motor and a servomotor

- $\quad 330 \Omega, 1 \mathrm{k} \Omega$ and $10 \mathrm{k} \Omega$ resistor, a Mosfet transistor and cables.

- How to obtain an analog magnitude from an accelerometer using an Arduino Board and plotting the results in a Desktop/Laptop computer?

- How to visualize acceleration values from an excited system in real time?

- How to control a 5V motor with an Arduino Board by using controllers such as buttons and potentiometers?

The core of this part is the design of two experiments: i) Free vibrations and ii) harmonic excitations in structural systems. Both experiments are performed in a cantilever steel beam of varying length and rectangular cross-section $20 \mathrm{mmx} 4 \mathrm{~mm}$. The steel plate is connected to a rigid table with adjustable clamping devices. Thus, students can manipulate the steel plate and adjust its length. In both experiments, a three-axis accelerometer is connected to an Arduino board. In experiment 1 (free vibrations, Fig. 5), an initial displacement $\mathrm{u}_{0}$ is applied in the tip of the cantilever. The system vibrates freely 

excites the system in a harmonic way. The speed of the motor is controlled with buttons and a potentiometer. Finally, schemes of the circuitries that are used for acquiring values of acceleration (Fig. 7(a)) and for controlling an actuator (a small motor) are provided (Fig. 7(b))

Hands-on construction and instrumentation of $3 D$ frames. editions of the educational experience.

Subsequently, the models are tested with 2D axis accelerometers at each story. The base motion is generated with a scale reduced modal exciter available in the laboratory facilities. The exciter provides a $0-20 \mathrm{~Hz}$ range available for frequency sweep. The base of each frame is clamped to the moving table. Harmonic amplified signals are provided to the actuator at varying values of frequency in order to analyze different vibration modes as well as in order to measure acceleration at each story. Resonance as well as different modes are activated for certain frequency values. Furthermore, the experience illustrates 
to the students how unavoidable misalignments during the frame construction may lead to undesired torsional modes. Figure 9 shows a scheme as well as a lateral view of the test deployment.

\section{Discussion of the educational experience}

The educational experience has been implemented in small groups ranging from 4 to 15 students from a Master Course of Construction Engineering. The methodology of some of these previous editions was not identical though. The results obtained so far when applying the depicted methodology prove satisfactory for small groups. Submissions of the compulsory homework are correct and their quality is remarkable. In small groups, however, the bonus submissions are not numerous so far. Figure 10 displays screenshots adapted from some examples of physical simulations. Moving frames, beams and pendulum are the main simulated systems. Concepts of damping, resonance, frequency and motion are inferred and studied from simulations. Figure 11 displays images of the experiments (both cantilever and frame) and some of the results submitted by students in form of adapted plots. During these experiences, the students face typical situations related to experimental mechanics such as: validation of results and difference between theory and tests, which is very valuable as an educational experience for the particular case of structural dynamics. The students analyzed different alternatives to which these discrepancies may be attributed to. Imperfect clamping of the elements, imperfect horizontality of the sensors and/or frame elements or asymmetries are generally the main reasons of these differences.

One key aspect of the educational experience is the feedback from students. Since this course also includes hours of theory and exercises within a regular classroom, it is possible to check the experimentally obtained results with those derived theoretically. As a result, a validation process is performed by students. It is worth pointing out that this validation process is useful not only for its own sake, but also, for testing the educational capabilities of the experience as a whole. When results obtained match, the students gain self-confidence about the whole experience. If 
conversely, these results do not match, students are entitled to enquire about potential mistakes (either theoretical or experimental). Concepts and methods are revisited and the educational experience is enriched.

Finally, it is worth pointing out that a more systematic assessment of the experience, including objective standard evaluation of the pedagogy is necessary if implemented in larger groups. Likewise, the extra activities suggested in table 1 as bonuses, are more likely to be performed by students in larger groups than in smaller ones.

\section{Reproduction of similar experience in classroom-based environments}

Similar educational experiences using DFM and physical simulations are feasible not only for structural dynamics but also for a broader scope of subjects. Processing and Arduino present a very similar programming environment and sending values from real sensors to Processing as input parameters is intuitive using OOVP. In this particular case, the animations consist of bodies in which acceleration changes velocity and velocity changes their location with time. These values of acceleration may be collected in real time from external sources or alternatively, defined by the user internally in the code. In other simple systems in which any animation variable may be defined by external inputs, Processing and Arduino match satisfactorily.

Arduino-wise, the key aspect in the experience is to teach how to collect analog magnitudes from sensors. This process is relatively straightforward. Values obtained with potentiometers or light dependent resistors are useful for beginners since these magnitudes can be altered and understood easily by the users. Once the signal magnitudes are collected, the key issue is to send it via serial port to the computer to be collected by Software. In Processing, an Arduino object must be declared and thus, methods related to collecting analog values from sensors can be applied to these objects. In this particular set of experiments, the construction part involves "hands-on" experimental hours with previous design of a structure using theoretical and numerical tools. The 
most important aspect in this part is to conceive a structure that may be excited appropriately by the laboratory facilities.

\section{Conclusions}

In this paper, a design of an experimental experience related to structural dynamics based upon DFM tools is presented. The classroom is designed in such a way that first, the students get acquainted with physics simulations using open-source codes. Second, a set of experiments with teaching purposes related to structural dynamics is reproduced using open-source low-cost electronics and third, a hands-on experience related to construction and instrumentation of scalereduced 3D building is performed. Several conclusions can be drawn from this work:

- From the structural analysis perspective, the experiments are designed with openelectronics platforms and easy-to-follow Software. The experiments may be useful in basic courses of structural dynamics with a particular emphasis on the behavior of structural systems subjected to free vibrations and to harmonic oscillations. Concepts such as damping, sweep frequency response analysis and resonance can be analyzed experimentally. The experiments can be performed in a classroom-based environment and if needed, the entire preparation of the material can be performed by students from scratch.

- From the engineering education perspective, the design of such experiments may provide added value to students in a manifold fashion: i) Students may start bridging the existing physical-to-digital gap in civil engineering schools. ii) Students may start fostering the potential entrepreneurial attitude that digital fabrication and open-source labs are expected to generate. iii) Students may start getting acquainted with the development of object oriented physics simulations with open platforms. Such tools are not yet universally known and used in civil engineering schools. 
- Education-wise, the experience includes a theory vs. experiments validation, which gives 
456 Adhikari S., Friswell M.I., Lonkar K., Sarkar A. (2009). "Experimental case studies for uncertainty

457 quantification in structural dynamics". Probabilistic Engineering Mechanics. Vol 24 (4). 473-492.

458 Arduino (2016) $<$ http://www.arduino.cc $>$ (Jun. $\left.6^{\text {th }}, 2016\right)$

459

460

Blanco E., Oller S., Gil L. (2007). Análisis Experimental de Estructuras. Ediciones CIMNE. Barcelona.

461 Spain. (In Spanish).

462

463

Chanson, H. (2004). "Enhancing Students' Motivation in the Undergraduate Teaching of Hydraulic

Engineering: Role of Field Works." J. Prof. Issues Eng. Educ. Pract., 10.1061/(ASCE)1052-

465 3928(2004)130:4(259), 259-268.

466

Chen H., Kurt M., Lee Y., McFarland D.M., Bergman L.A., Vakakis A. (2014). "Experimental system identification of the dynamics of a vibro-impact beam with a view towards structural health monitoring and damage detection”. Mechanical Systems and Signal Processing. Vol 46 (1). 91-113.

470

Chopra A. (2007). Dynamics of Structures. Theory and Applications to Earthquake Engineering. Third Edition. Pearson Prentice Hall. New Jersey. USA.

473

Clough R., Penzien J. (2003). Dynamics of Structures. Third Edition. McGraw Hill. Berkeley. USA.

Cruz-Martín A., Fernández-Madrigal J.A., Galindo C. , González-Jiménez J., Stockmans-Daou C., Blanco-

Claraco J.L. (2012). "A LEGO Mindstorms NXT approach for teaching at Data Acquisition, Control Systems Engineering and Real-Time Systems undergraduate courses". Computers and Education. Vol 59 (3). 974-988. and research". Computer applications in engineering education. Vol 13 (1). 99-110. 

Environmental Monitoring Applications". Procedia Computer Science. Vol 34. 103-110.

486

Fox S. (2014). "Third Wave Do-It-Yourself (DIY): Potential for prosumption, innovation, and entrepreneurship by local populations in regions without industrial manufacturing infrastructure" Technology in Society. Vol 39 (11). 11-30. measurement systems". Computer Applications in Engineering Education, 15 (2). 174-184.

492

Ionescu C.M., Fabregas E., Cristescu S.M., Dormido S., De Keyser R. (2013). “A remote laboratory as an innovative educational tool for practicing control engineering concepts" Education, IEEE Transactions.

496

Katsanos E.I., Taskari O.N., Sextos O.A (2014). “A matlab-based educational tool for the seismic design of flexibly supported RC buildings". Computer applications in engineering education. Vol 22 (3). 442-451.

499

500 Kensek K.M. (2014). "Integration of environmental sensors with BIM: case studies using Arduino, Dynamo, and the REVIT API”. Informes de la Construcción. Vol 66 (536), e044.

502

503

Koenka I., Sáiz J., Hauser P. (2014). "Instrumentino: An open-source modular Python framework for controlling Arduino based experimental instruments". Computer Physics Communications. Vol 185(1).

505 2724-2729.

506

507

LabView (2016). $<$ http://www.ni.com/labview/> (Jun. $\left.6^{\text {th }}, 2016\right)$

508

509

Matlab (2016). $<\underline{\text { http: } / / \text { www.mathworks.com }>(J u n . ~} 6^{\text {th }}, 2016$ )

510

511

MIT Video website (2016). $<$ http://video.mit.edu $>$ (Jun. $\left.6^{\text {th }}, 2016\right)$ 
"MOOC Coursera. Design, create, and deploy a fun IoT device using Arduino and Raspberry Pi platforms",

] Nakazawa T., Matsubara M., Mita S., Saitou K. (2014). “Teaching Materials and Lessons Plans for Hands-

On Mechanics Education”. Experimental Techniques. Vol 38 (6). 72-80.

518

Ozcelik O., Attar P., Altan M.C., Johnston J.W. (2013). "Experimental and numerical characterization of the structural dynamics of flapping beams". Journal of Sound and Vibration. Vol 332 (21). 5393-5416.

521

Paz M, Leigh W. (2003). Structural Dynamics: Theory and Computation. 5th Edition. Springer. New York USA.

524

Pearce J. (2014). Open-Source Lab. How to Build Your Own Hardware and Reduce Research Costs. 1st

Edition. Elsevier. USA-UK-The Netherlands. 2014

527

Processing 2.0. (2016). $<$ http://processing.org $>$ (Jun. $\left.6^{\text {th }}, 2016\right)$

529

Python 3.5 (2016). . $<$ http://www.python.org $>$ (Jun. $\left.6^{\text {th }}, 2016\right)$

531

Raspberry Pi (2016). < http://www.raspberrypi.org $>$ (Jun. $6^{\text {th }}, 2016$ ) press. USA.

Senatore G., Piker D. (2015). "Interactive real-time physics: An intuitive approach to form-finding and structural analysis for design and education”. Computer-Aided Design. Vol 61 (4). 32-41.

538

539 Shiffman D. (2016). Online HTML and tutorial-based book, The nature of code. 
542 Solís, M., Romero, A., and Galvín, P. (2012). "Teaching Structural Analysis through Design, Building, and

543 Testing." J. Prof. Issues Eng. Educ. Pract., 10.1061/(ASCE)EI.1943-5541.0000097, 246-253.

544 Unterweger, H. (2005). "Simple Structural Models for the Education of Structural Engineers at Graz

545 University." J. Prof. Issues Eng. Educ. Pract., 10.1061/(ASCE)1052-3928(2005)131:4(227), 227-230.

546

547 Valera A., Soriano A., Vallés M. (2014). "Plataformas de Bajo Coste para la Realización de Trabajos 548 Prácticos de Mecatrónica y Robótica”. Revista Iberoamericana de Automática e Informática Industrial.

549 Vol 11(4). 363-376.

550

551

552

553

554

555

556

557

558

559

560

561

562

List of tables and figures (Captions) 
P Damping | Processing 2.2.1

File Edit Sketch Tools Help

○O무부

Damping $\odot$

void $\operatorname{setup}()\{$

$1 /$ put your setup code here, to run once:

size $(1200,1000)$;

background $(0,0,0)$;

\}

void draw() \{

// put your main code here, to run repeatedly:

fill(255);

$\operatorname{rect}(500,500,100,100)$

563

\}

564 Fig. 1. Processing (a) and Arduino (b) Integrated Development Environment

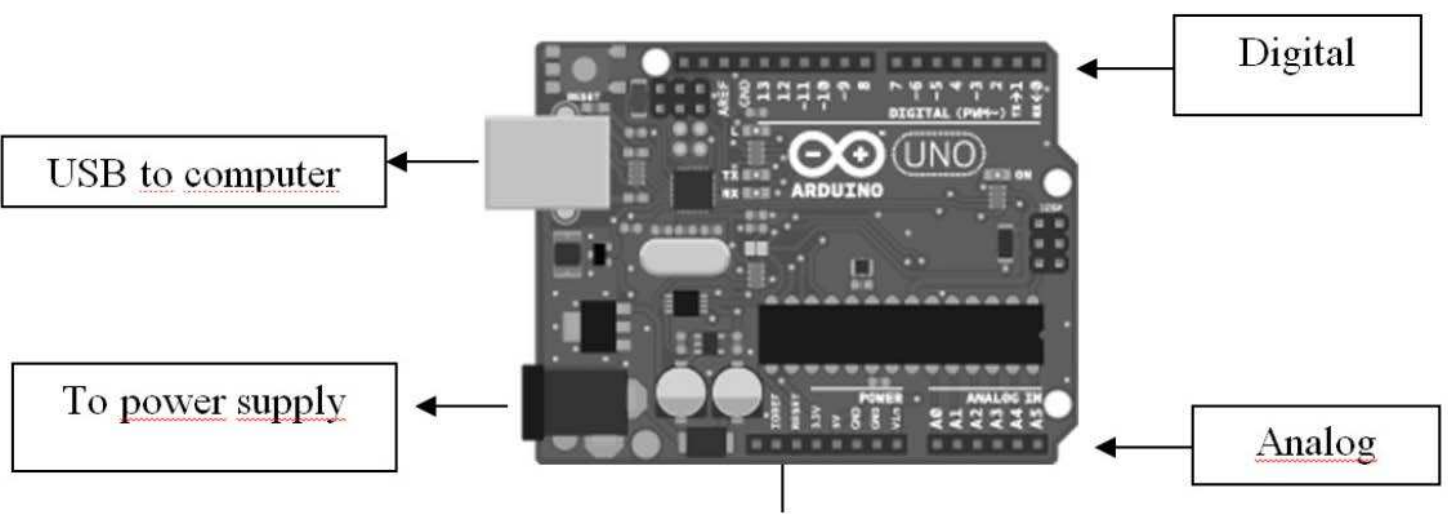

565

Fig. 2. The Arduino/Genuino UNO board.
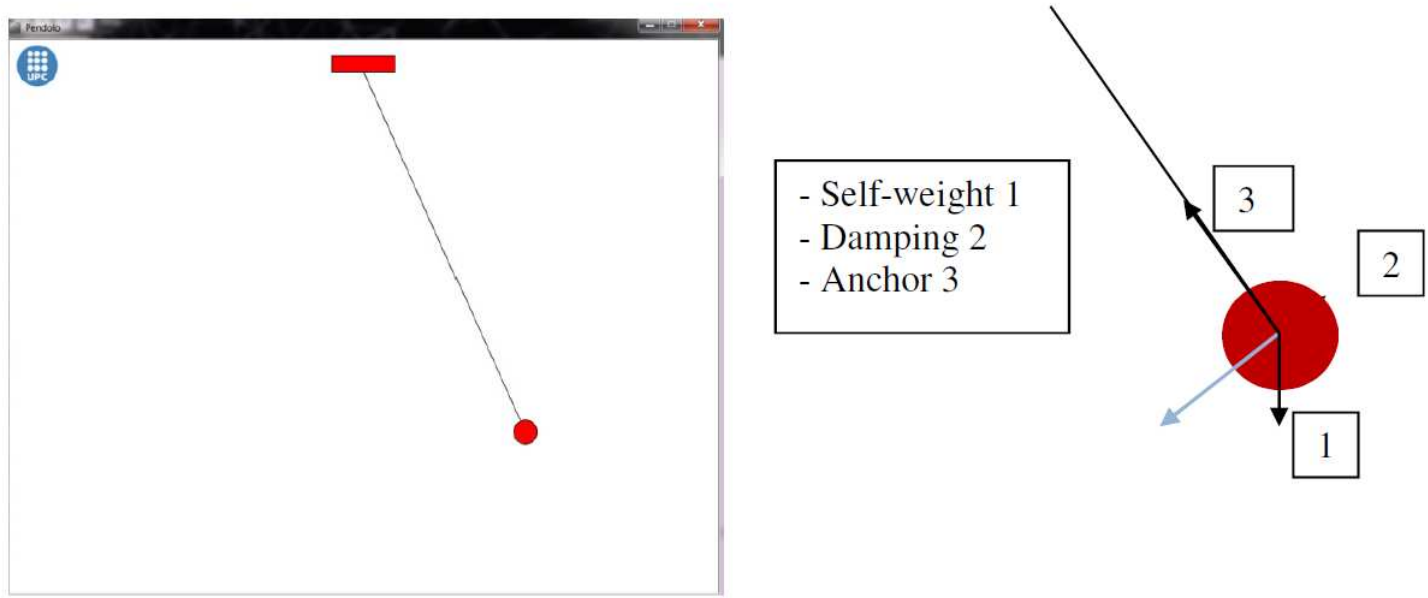

567

Fig. 3. Pendulum in processing. Anchor, rod and mass.
0) damping | Arduino 1.6.7

File Sketch Tools Help

\section{$\nabla \oplus \mathbb{0} \pm$}

damping $\S$

void setup () i

// put your setup code here, to run once:

Yoid loop()

// put your main code here, to run repeatedly: 


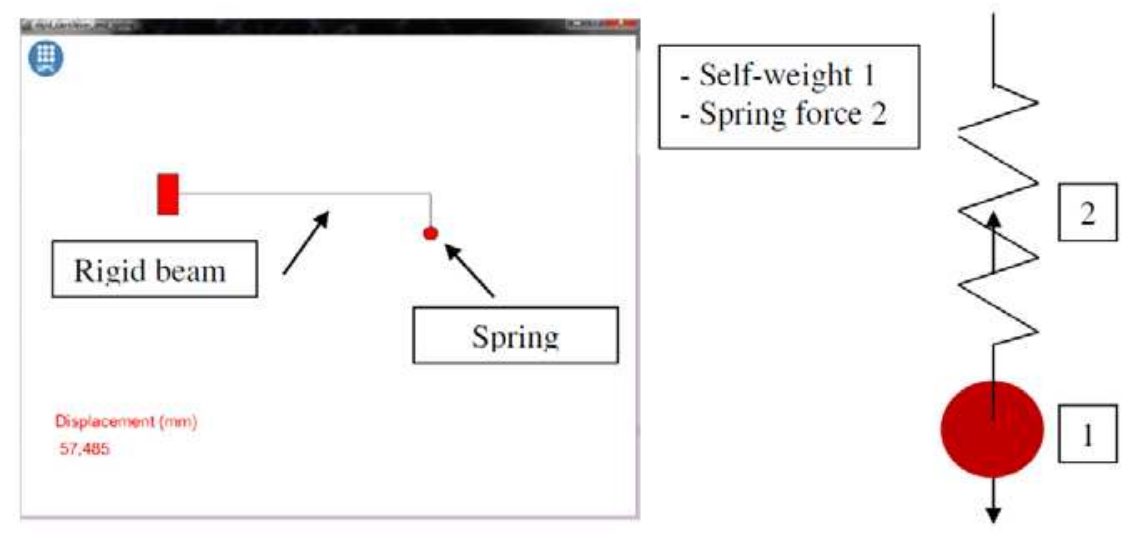

569

570 Fig. 4. Spring in Processing. Rigid beam, spring and mass.

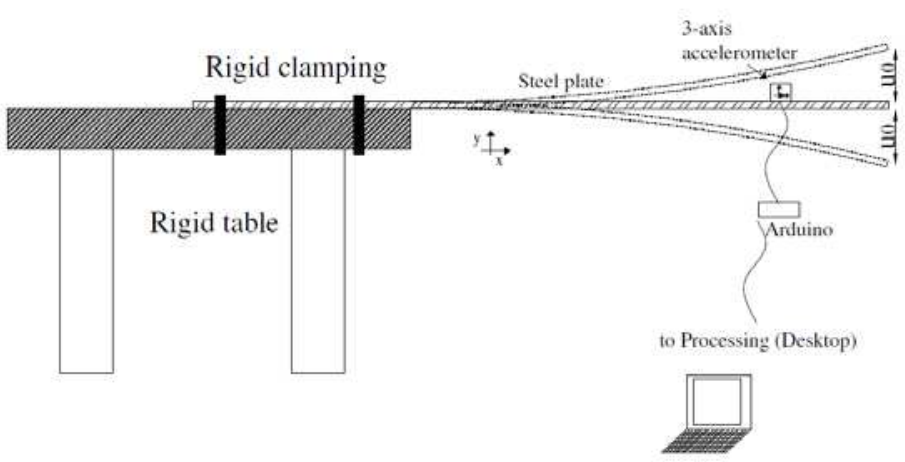

571

572 Fig. 5. Free vibrations. Connections and general view of the experimental setup

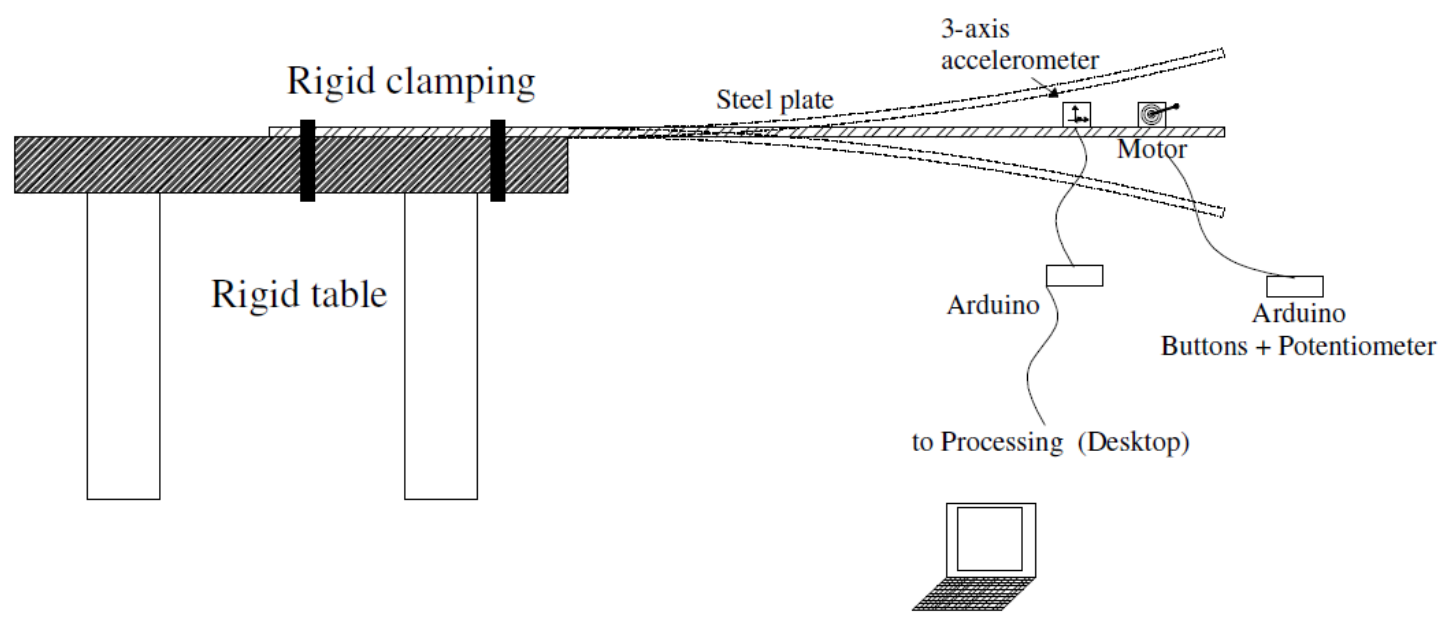

574 Fig. 6. Harmonic oscillations. Connections and general view of the experimental setup 

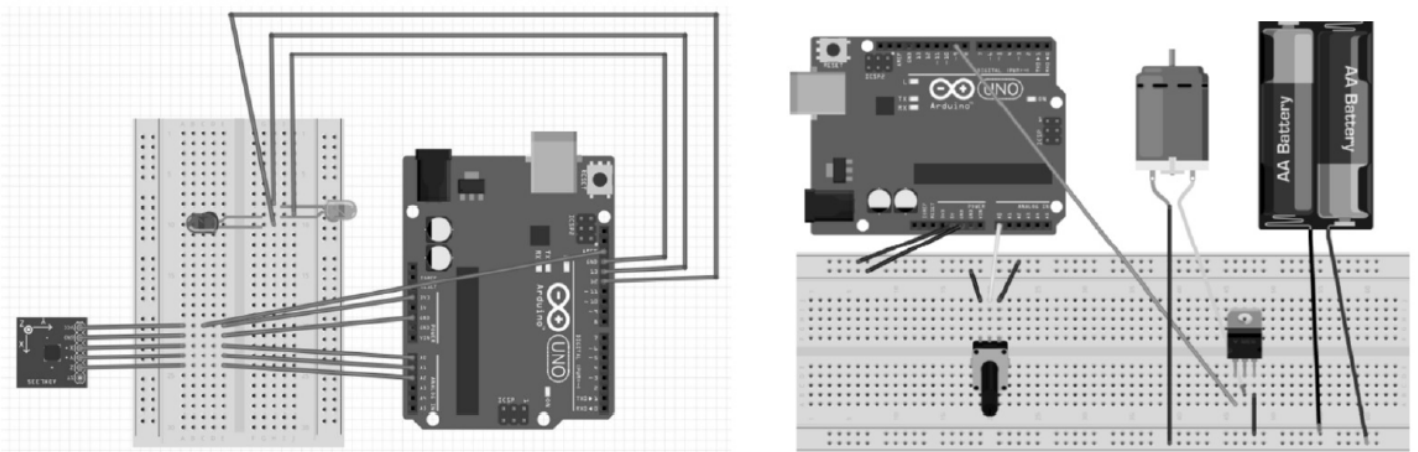

576

577 Fig. 7. Arduino circuitries (a) Acquiring acceleration analog magnitudes (b) Control of actuator
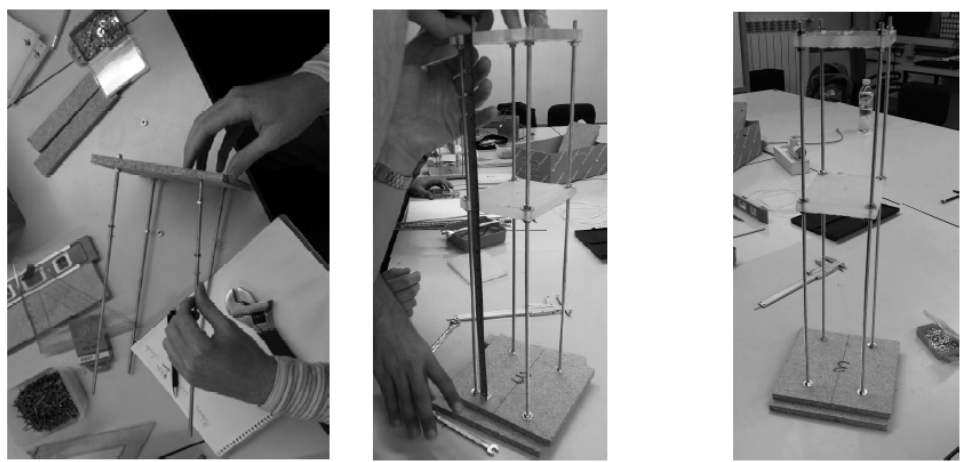

579 Fig. 8. Construction of 3D frames with variable materials, masses and geometries

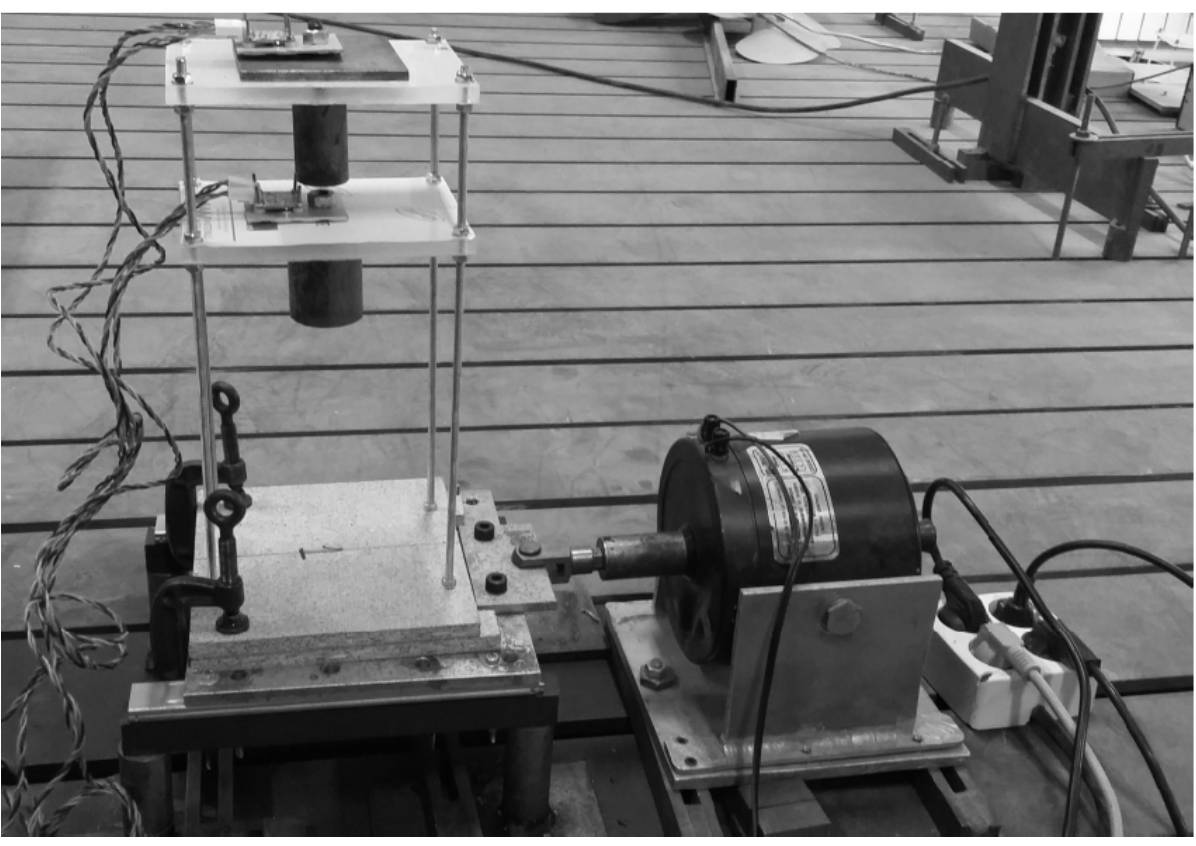

Fig. 9. Scale-reduced test of 3D frames subjected to harmonic oscillations 


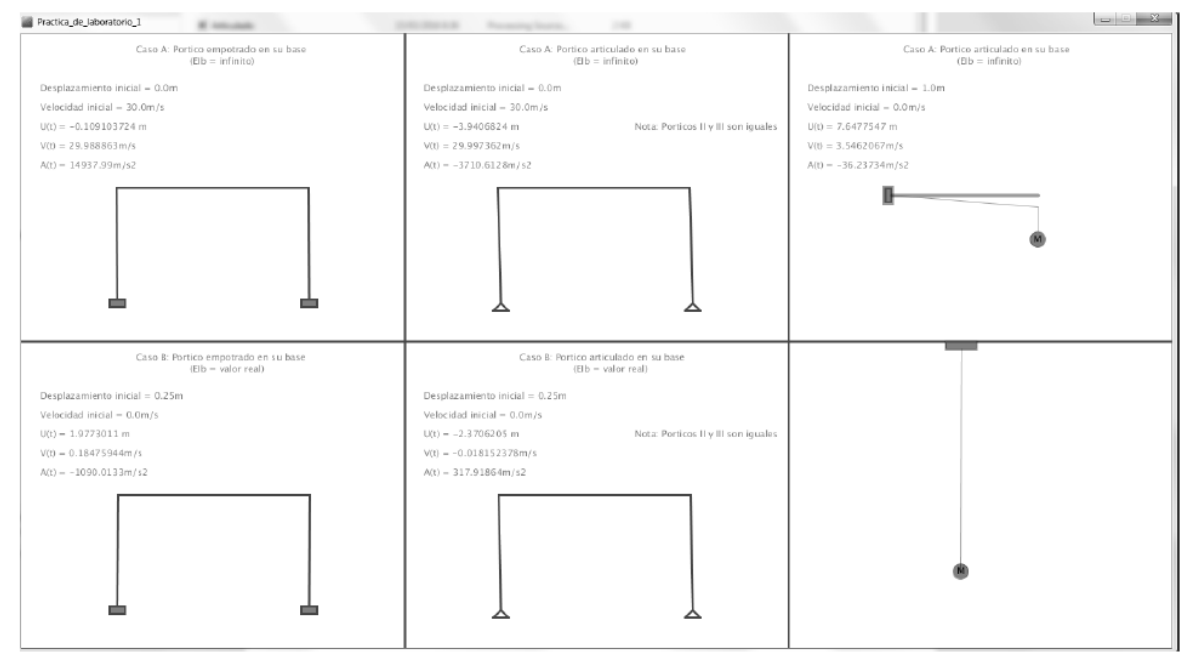

584

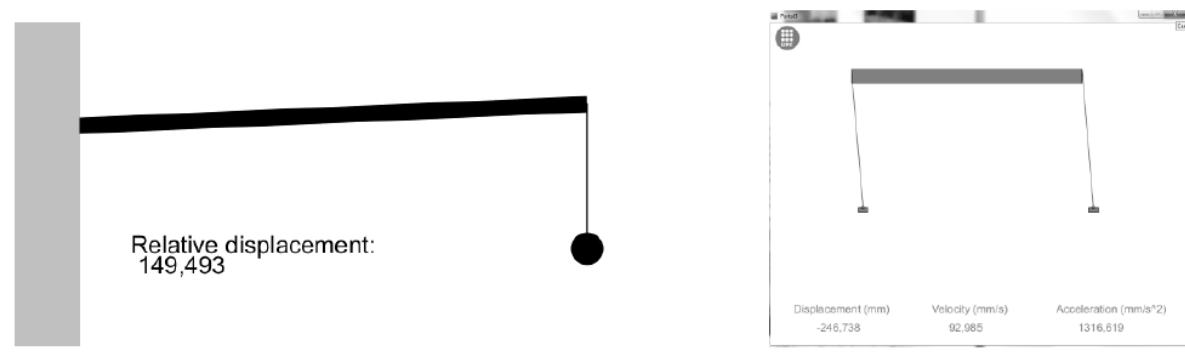

585 Fig. 10. Drawings adapted from submitted codes including frames, beams and springs.
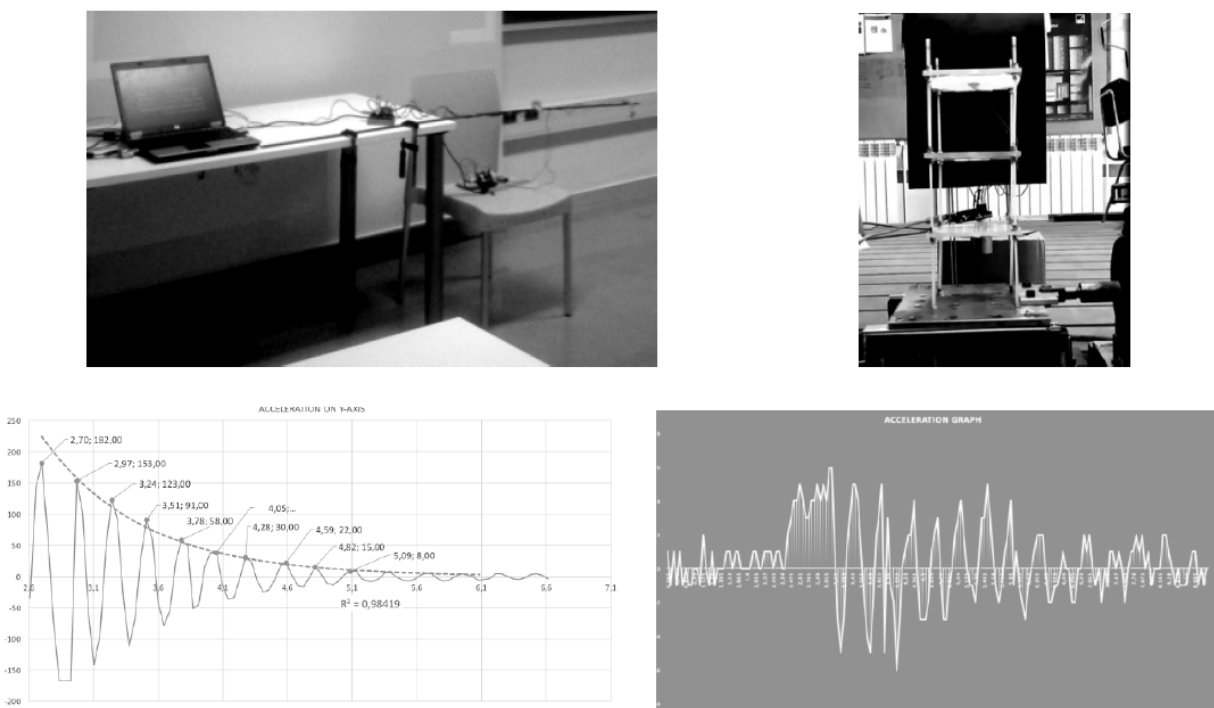

586

Fig. 11. Illustrative results adapted from submitted data 


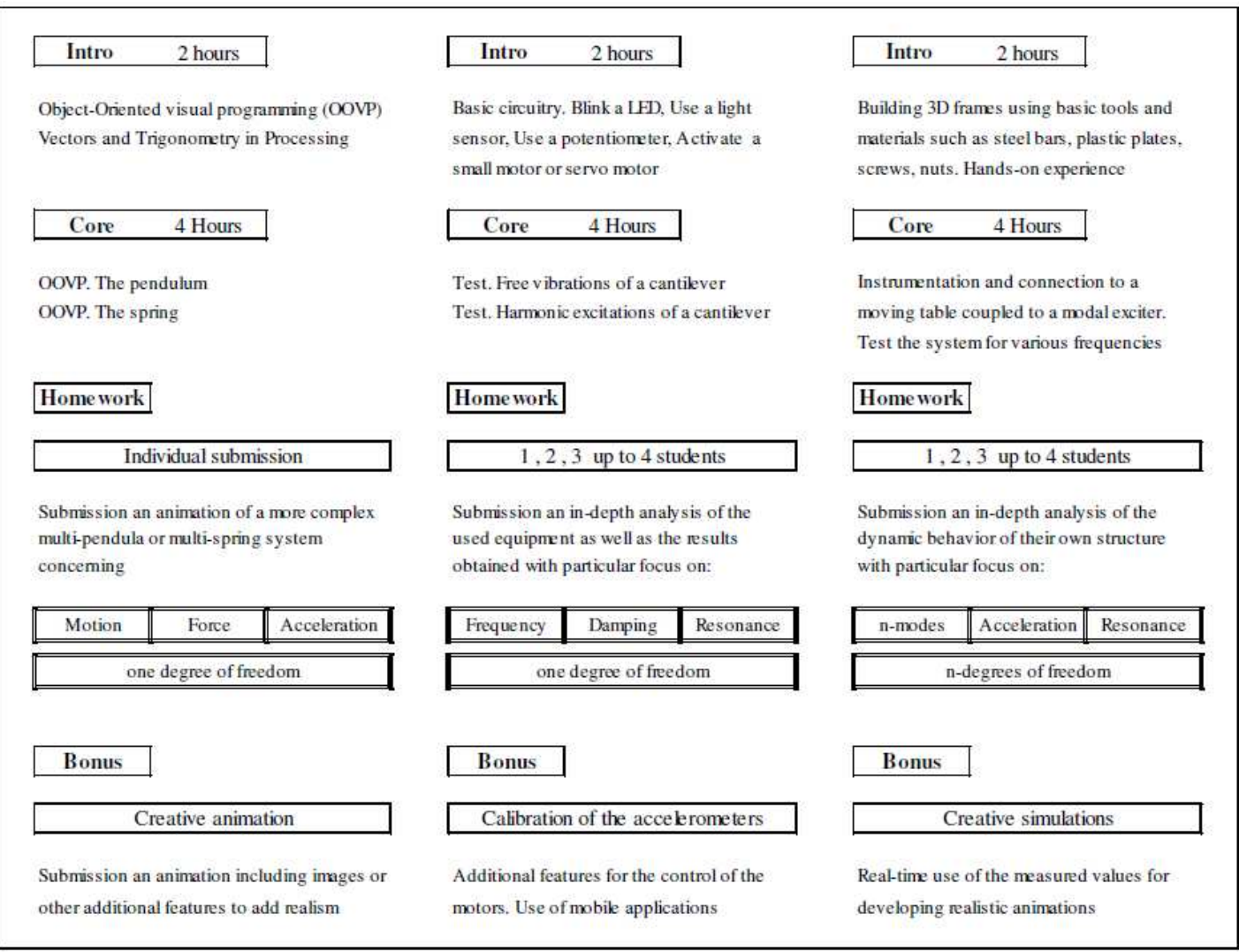

593 Table 1. Organization of the educational experience 